\title{
Dynamic testing of cable structures
}

\author{
Elsa Caetano ${ }^{1, a}$ and Álvaro Cunha ${ }^{1}$ \\ ${ }^{1}$ University of Porto, Faculty of Engineering, R. Dr. Roberto Frias, 4200-465 Porto, Portugal
}

\begin{abstract}
The paper discusses the role of dynamic testing in the study of cable structures. In this context, the identification of cable force based on vibration measurements is discussed. Vibration and damping assessment are then introduced as the focus of dynamic monitoring systems, and particular aspects of the structural behaviour under environmental loads are analysed. Diverse application results are presented to support the discussion centred on cable-stayed bridges, roof structures, a guyed mast and a transmission line.
\end{abstract}

\section{Introduction}

The construction of lightweight structures covering progressively longer spans and employing cables as supporting elements has increased worldwide, leading to very flexible applications in bridges, roofs and special structures. These are generally characterised by complex structural behaviour, marked by a significant geometric nonlinearity, high deflections under service loads, a high number of vibration modes closely spaced in frequency, several of which of local nature, and proneness to vibrations induced by wind, traffic and human actions.

The fact that the geometry and the structural behaviour of flexible lightweight structures is determined by the level of cable pre-stress makes their construction complex, demanding the accurate installation of prestress. This often determines the need for assessment of cable force during and after construction and is particularly relevant for roof structures and cable-stayed bridges.

Referring to the dynamic behaviour of cable structures, and despite the enormous developments of the last decades, several phenomena behind cable vibrations are still not entirely mastered and episodes of cable and structure vibrations have been frequently reported all over the world. The number of cables involved and the complexity of occurrences have put a strong demand in terms of vibration assessment and on the implementation of monitoring systems.

Finally, the need to detect damage at early stages, enhanced by the potential fatigue effects caused by vibrations, constitute an additional argument to the present trend to monitor the structural behaviour of important infrastructures.

This paper aims at discussing the various aspects of dynamic testing and monitoring above mentioned in the context of cable structures. So, dynamic testing techniques applied for the identification of force in cables will be first addressed. In a second phase, techniques for the assessment of damping and cable vibrations will be discussed. Finally, the continuous dynamic monitoring of cable structures will be focused based on an application on a suspension roof structure.

\section{Identification of cable force}

Identification of cable force based on vibration measurements was first proposed by Mars and Hardy [1], who defined a methodology supported by the relation between the installed force and the cable vibrating frequency. This relation results from the establishment of the dynamic equilibrium equation of the cable idealised as a tensioned beam under different end conditions. Accordingly, a simple supported cable with uniformly distributed mass per unit length $\mathrm{m}$ and length $\ell$, tensioned with a force $T$, vibrates with a natural frequency of $i^{\text {th }}$ order $\mathrm{f}_{\mathrm{si}}$ defined by

$$
f_{s i}=\frac{i}{2 \ell} \cdot \sqrt{\frac{T}{m}}
$$

Therefore, if the mechanical characteristics of the cable are known and one of the cable vibration frequencies is measured, an estimate of the force $\mathrm{T}$ can be obtained by application of expression (1). In the case of a cable clamped at both ends, the $i^{\text {th }}$ order natural frequency can be defined in simplified form as

$$
f_{i}=f_{s i} \cdot\left(1+\varepsilon_{E I}^{i}\right)
$$

The quantity $\varepsilon_{E I}^{i}$ in this expression is given by

$$
\varepsilon_{E I}^{i}=\frac{2}{\zeta}+\frac{4+\frac{i \pi^{2}}{2}}{\zeta^{2}}
$$

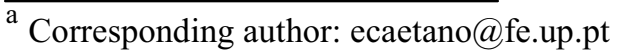


where $\zeta$ is the normalised bending parameter, defined as $\zeta=\sqrt{T \ell^{2} / E I}$ and EI represents the cable bending stiffness. As for the simple supported cable, if the mechanical characteristics of the cable are known, including in this case the bending stiffness EI, the measurement of one cable frequency can provide one estimate of the cable force.

In practice, the bending stiffness effect may be disregarded in many circumstances. Introducing the criterion that this effect is negligible whenever $\varepsilon_{E I}^{i}$ is less than $5 \%$ for the first five modes, it can be concluded that bending effects can be neglected as long as $\zeta \geq 50$ [2]. Therefore the designated vibrating chord formula expressed by (1) can be alternatively applied to estimate the installed cable force. The validity of the application of the vibrating chord formula to several cables used in civil engineering applications was investigated by Robert et al [3], who verified that for a wide range of situations, mostly related with stays from cable-stayed bridges, this simple formula can provide very accurate estimates of the installed forces. For this reason, this methodology of identifying cable force based simply on the measurement of the first few harmonics of vibration of a cable and on the knowledge of the corresponding mass and length, has been widely used for construction purposes or else for verification and correction of cable force after construction [4-7]. With some improvements, this methodology has also been applied to more complex cases, involving very long sagged cables, short stiff cables, low tensioned cables, cables anchored on flexible supports and groups of clamped cables. For these cases, specific formulae based on simplified analytical solutions have been used [8-11], as well as numerical formulations allowing the identification of various cable parameters from the measurement of sets of natural frequencies and from particular assumptions respecting the boundary conditions [12-14]. Considering applications in low sagged cables, typical from long span cable-stayed bridges, it is relevant to cite the simplified formulae derived by Mehrabi and Tabatabai [10]. Accordingly, the $i^{\text {th }}$ order natural frequency of a cable $f_{n}$ is given by

$$
f_{i}=\frac{i}{2 \ell} \cdot \sqrt{\frac{T}{m}} \cdot\left(\alpha \beta_{i}-0.24 \frac{\mu}{\zeta}\right)
$$

with

$$
\begin{aligned}
& \alpha=1+0.039 \mu ; \beta_{i}=1+\frac{2}{\zeta}+\frac{\left(4+\frac{i \pi^{2}}{2}\right)}{\zeta^{2}} \\
& \mu=\lambda^{2}, i=1 ; \mu=0, i>1 \text { (in-plane modes); } \\
& \mu=0 \text { (out-of-plane modes) }
\end{aligned}
$$

The quantity $\lambda^{2}$ in these expressions is the so-called Irvine parameter $\lambda^{2}$, defined as [15]

$$
\lambda^{2}=\left(\frac{m g \ell}{T}\right)^{2} \cdot \frac{\ell}{\frac{T L_{e}}{E A_{0}}}
$$

where $\mathrm{EA}_{0}$ represents the cable axial stiffness and $L_{e}$ is a virtual length of cable given by

$$
L_{e}=\int_{0}^{\ell}\left(\frac{d s}{d x}\right)^{3} d x \approx \ell \cdot\left\{1+8\left(\frac{d}{\ell}\right)^{2}\right\}
$$

The formulae derived in [10] include simultaneously sag and bending stiffness effects and are most accurate for cables with a $\zeta$ value no less than 50 and with an Irvine parameter $\lambda^{2}$ of less than 3.1. Mehrabi and Tabatabai refer that these restrictions are covered by $95 \%$ of the stay cables from cable-stayed bridges around the world.

It should still be pointed that, even if these formulations adequately represent the dynamic characteristics of cables for ranges of dispersive behaviour, there remains uncertainty with respect to the definition of some parameters. These are namely the exact degree of constraint at the anchorages, the bending stiffness EI (that depends itself on the cable deformation and tension) and, eventually, the exact cable length. Moreover, given that experimental techniques have immensely improved in recent years, it is presently possible to obtain very accurate estimates of cable frequencies for many vibration modes other than the first two. This allows the simultaneous identification of force and some of the uncertain governing parameters, using optimisation criteria and curve fitting techniques ([12], [13], [16]. On the other hand, considering also the progress in the numerical modelling of complex structures, the combination of numerical models with experimental testing and identification techniques can provide an extremely powerful tool in the estimation of cable force for applications characterised by significant dispersive behaviour([14], [16]), as will be subsequently illustrated.

Nevertheless, even if several other more sophisticated methods are presently available for identification of cable force, the application of formulae (1), (2) and (4) provides initial approximations of the force estimates, as well as the order of magnitude of the secondary effects, as sag, bending effects and support conditions.

Complementarily, the error associated with the cable force estimate $\left(\varepsilon_{\mathrm{T}}\right)$ can be defined approximately as a function of the errors associated with the frequency $\left(\varepsilon_{\mathrm{f}}\right)$, the cable length $\left(\varepsilon_{\mathrm{L}}\right)$ and mass $\left(\varepsilon_{\mathrm{m}}\right)$ according to

$$
\varepsilon_{T}=2 \varepsilon_{f}+2 \varepsilon_{L}+\varepsilon_{m}
$$

As the cable mass is generally well defined, the parcel $\varepsilon_{\mathrm{m}}$ in (7) can be neglected. On the contrary, attention should be focused on the errors $\varepsilon_{\mathrm{f}}$ and $\varepsilon_{\mathrm{L}}$. The error in the determination of cable frequencies depends on the signalto-noise level and on the measurement parameters. The latter can be specified in order to guarantee that the 
frequency estimation error is no greater than $0.5 \%$, so that the error introduced in the force estimate due to frequency identification is no greater than $1 \%$, provided that the signal to noise ratio is low and therefore no doubt exists on the identification of natural frequency. Therefore, if the purpose is to identify the cable force with an error of $5 \%$, then $\varepsilon_{\mathrm{L}}$ should not exceed $2 \%$.

Having these aspects into consideration, it is possible to verify the adequacy of application of a particular formulation to a specific cable and, most important, provide possible intervals of incertitude associated with force estimate. In order to illustrate this, some examples of application are described.

Regarding the applicability of the vibrating chord method as described by expression (1), experience has shown that, for cables from cable-stayed bridges, very high accuracy can be achieved for lengths of $50 \mathrm{~m}$ to 200 $\mathrm{m}$. In effect, these cables are normally highly tensioned, with stress levels of at least $500 \mathrm{MPa}$, their length is relatively large so that the uncertainties in the definition of the fixed position at the ends are not relevant in terms of the error $\varepsilon_{\mathrm{L}}$ (a reasonable error in the length definition of $\pm 0.70 \mathrm{~m}$ considering that the fixed position of the cables is an intermediate point located between the anchorage and the neoprene ring inside the deviator guide tubes results in $\varepsilon_{\mathrm{L}}=1.4 \%$ for the shortest length of $50 \mathrm{~m}$ ), the diameter, typically no greater than $250 \mathrm{~mm}$ for this length interval, leads to bending stiffness parameters greater than 100, therefore to negligible bending effects in the assessment of cable force and, finally, sag effects are also negligible, given the typical Irvine parameters lower than 0.5. An example is presented referring to two cables of the International Guadiana Bridge, in Portugal, with a main span of $324 \mathrm{~m}$ [17] (Fig. 1). The force estimates (T), systematised in Table 1 for the shortest and the $4^{\text {th }}$ longest cables of this bridge, have been obtained from a finite element model calibrated using the first 8 or 16 frequency peaks of measured power spectral density (PSD) functions, respectively. Fig. 2 shows the PSD estimate obtained from the in-plane accelerations measured at the $4^{\text {th }}$ longest cable, close to the deck anchorage. The error in the force estimate $\varepsilon_{\mathrm{T}}$ based on the application of the vibrating chord theory is of the order of $3 \%$, considering the incertitude in the definition of the cable distance between fixed points of $0.70 \mathrm{~m}$ and the error of $0.5 \%$ in the frequency identification. The sag effect associated with the Irvine parameters of 0.16 and 0.04 leads to a first frequency increase (with regard to the vibrating chord frequency) of the order of $0.6 \%$ for the longest cable, if expression (4) is considered. As for bending stiffness effects, considering the inertia of $7 \%$ of that corresponding to the cable full cross-section (calculated from the fitting of the first 16 frequencies in the case of cable 4) and the first five vibration modes, the increase in the cable frequency defined by formula (2) with regard to the vibrating chord formula (1) is of the order of $0.7 \%$ and $2 \%$ for the longest and the shortest cables, respectively, meaning that the non-consideration of bending effects would produce an additional error in the force estimate of the order of $1.4 \%$ and $4 \%$ for the stay cables. This result is consistent with the linear trend displayed by the plot of successive cable frequencies with the mode order represented in Fig. 3.

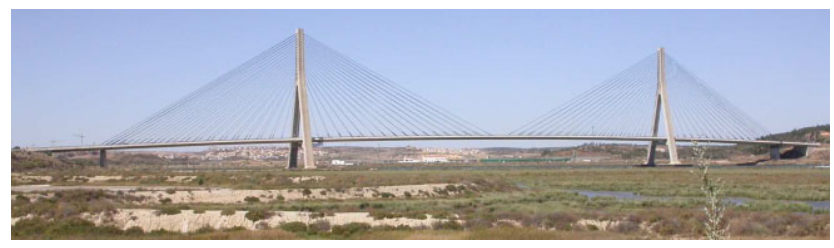

Figure 1. International Guadiana Bridge, Portugal

Table 1. Characteristics of Guadiana bridge cables

\begin{tabular}{|c|c|c|c|c|c|}
\hline $\begin{array}{c}\text { Cable } \\
\text { no. }\end{array}$ & $\begin{array}{c}\text { Length } \\
(\mathbf{m})\end{array}$ & $\boldsymbol{\lambda}^{\mathbf{2}}$ & $\boldsymbol{\zeta}$ & $\mathbf{T}(\mathbf{k N )}$ & $\boldsymbol{\varepsilon}_{\mathbf{T}(\%)}$ \\
\hline 4 & 148.69 & 0.16 & 295 & 3067 & 3 \\
\hline 16 & 48.69 & 0.044 & 108 & 1641 & 3 \\
\hline
\end{tabular}

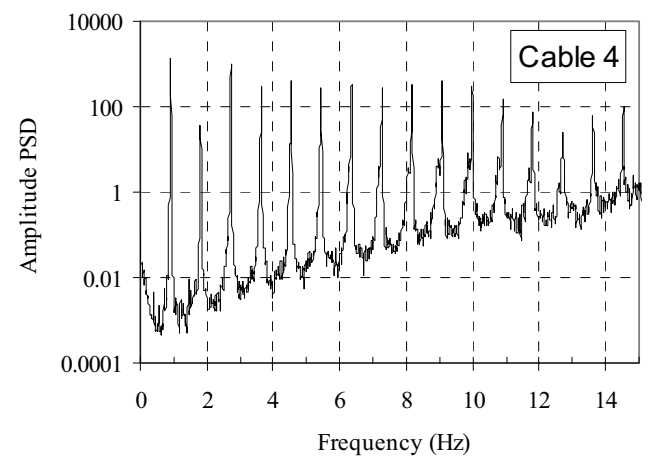

Figure 2. PSD function of accelerations at the Guadiana Bridge $4^{\text {th }}$ longest cable

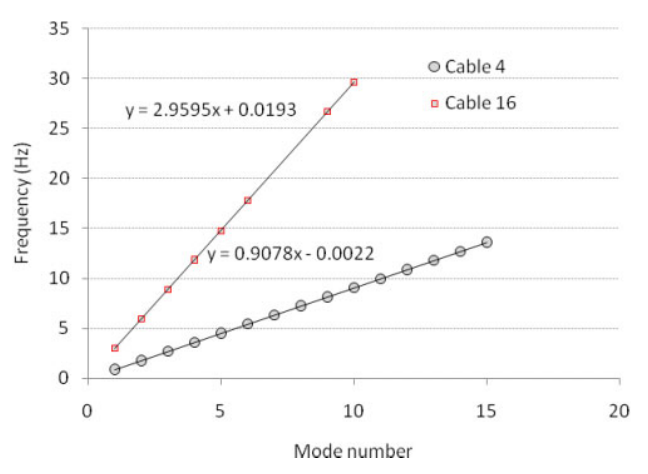

Figure 3. Variation of cable frequency with mode order for cables 4 and 16 of Guadiana Bridge.

Considering applications different than cable-stayed bridges, the length interval for optimal applicability of the vibrating chord formula (1) may differ from the above mentioned, depending on the characteristics of cables and anchorages. This can be exemplified with the circumferential cables stabilizing the lighting towers at the London 2012 Olympic stadium [7]. Fig. 4 shows images of such cables, with lengths of the order of $47 \mathrm{~m}$, diameter of $35 \mathrm{~mm}$ and stresses of the order of $190 \mathrm{MPa}$. The FFT of an ambient vibration acceleration record and the representation in Fig. 5 of the linear variation of the identified frequency peaks with the mode order once more evidence the applicability of the vibrating chord formula. In this case, the error of $\pm 0.10 \mathrm{~m}$ in the 
definition of the fixed length between cable ends results in an error length $\varepsilon_{\mathrm{L}}$ no greater than $0.5 \%$. Furthermore, using again formulae (2) to (4), sag and bending effects would produce an increase of the fundamental frequency of the order of $1.7 \%$ with regard to the vibrating chord frequency, therefore the non-consideration of these effects in the assessment of the force would still be acceptable.
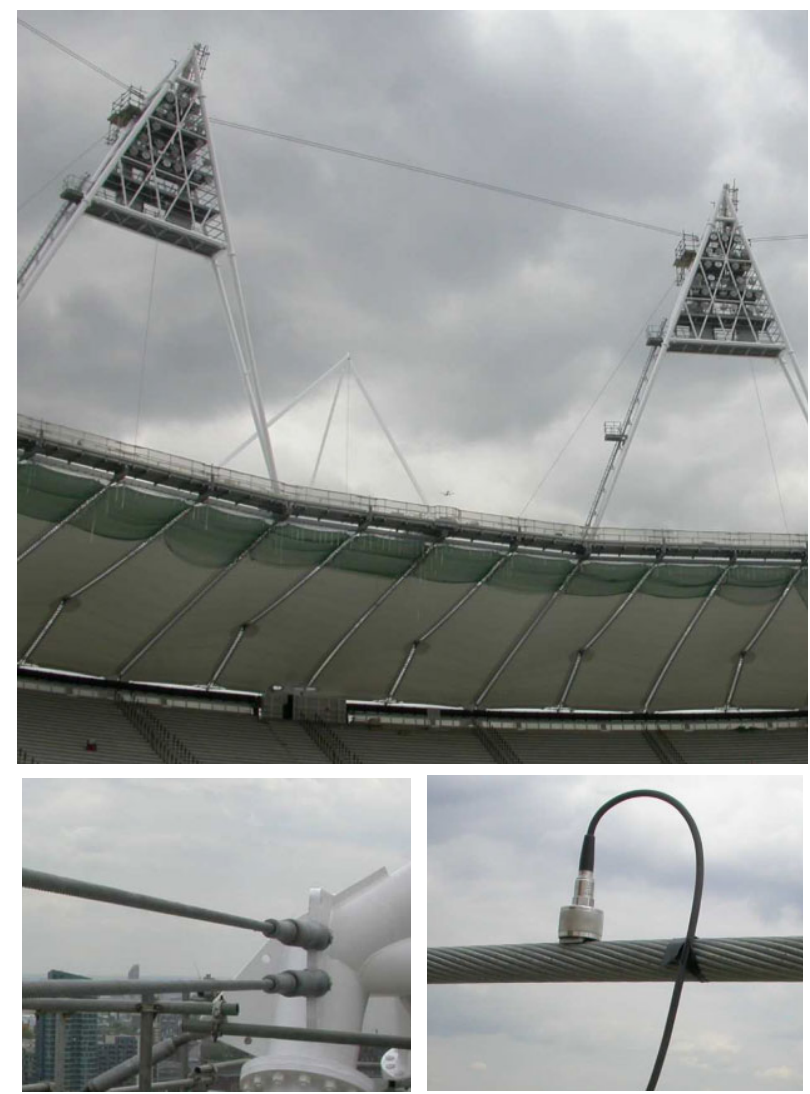

Figure 4. London 2012 Olympic stadium roof, circumferential cables at the lightning lowers.

The question is now how to treat short or highly sagged cables. Fig. 6 shows one image of the Viaduto do Comboio cable-stayed bridge, in the island of Madeira, which cables have lengths of 18 to $49 \mathrm{~m}$. In order to evaluate the possibility to obtain accurate estimates of cable force, numerical models were developed for three of the stay cables, the shortest, the longest and an intermediate length cable. These were first discretised as series of 100 truss or beam elements, simply supported or clamped at the ends. By applying an initial strain defined iteratively so as to approximate the frequencies identified experimentally and by constructing the tangent stiffness matrices under dead load configuration, the natural frequencies of the cables were determined and compared. Table 3 shows the results obtained for the intermediate length cable, either modelled as flexible (1), or else with a bending stiffness defined by the sum of the inertia of the individual strands (2). The comparison between the frequencies identified experimentally (Exp.) and the ones obtained on the basis of these models allows the conclusion that the bending stiffness of the cable cannot be higher than the one specified in the analysis (2). Furthermore, the comparison between the first four frequencies for models (1) and (2) shows that the bending stiffness induces in this cable an increase of frequency of the order of $0.4 \%$. In fact, considering the short and longest cables, the bending effect in the first four frequencies varies from $0.3 \%$ (longest) to $0.9 \%$ (shortest). Using simplified formula (2) bending effects of $2 \%$ to $4 \%$ are estimated for these same cables. So even though these cables are relatively short and stiff, it appears that the application of formula (2) is conservative in terms of predicting bending stiffness effects higher than the real ones.
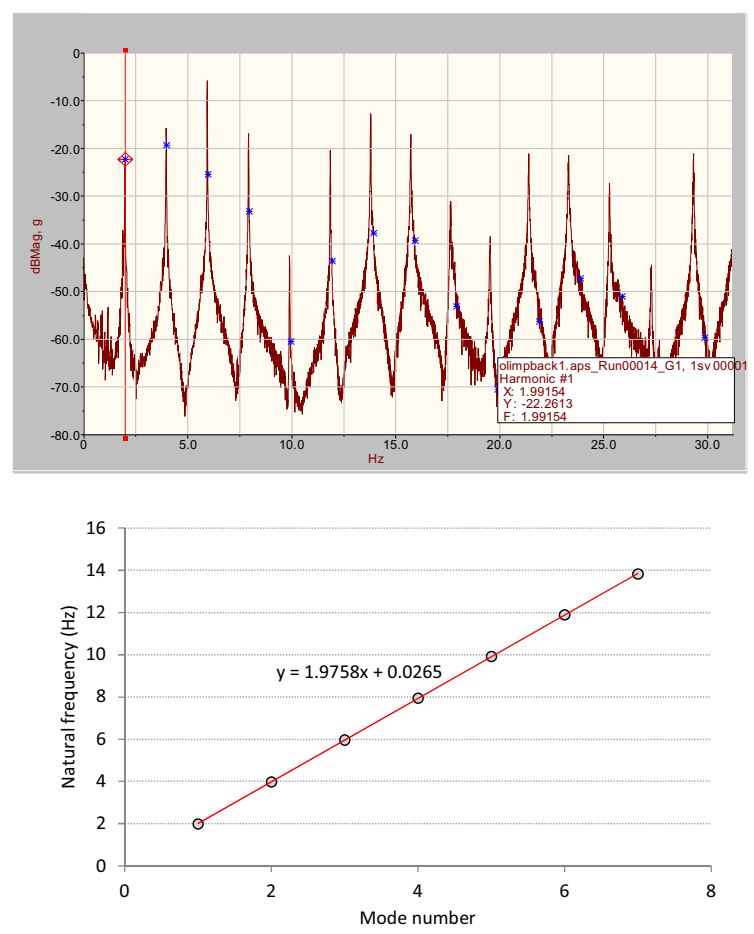

Figure 5. London 2012 Olympic stadium roof. FFT of ambient record collected in a circumferential cable and plot of identified frequency vs cable mode

Table 2. Characteristics of London 2012 Olympic stadium roof cables

\begin{tabular}{|c|c|c|c|c|c|}
\hline Cable & $\begin{array}{c}\text { Length } \\
(\mathbf{m})\end{array}$ & $\boldsymbol{\lambda}^{\mathbf{2}}$ & $\boldsymbol{\zeta}$ & $\mathbf{T}(\mathbf{k N )}$ & $\boldsymbol{\varepsilon}_{\mathbf{T}(\%)}$ \\
\hline Circumferential & 47.345 & 0.14 & 182 & 189 & 2 \\
\hline Tension ring & 5.173 & 0.00001 & 18.8 & 1404 & \\
\hline
\end{tabular}

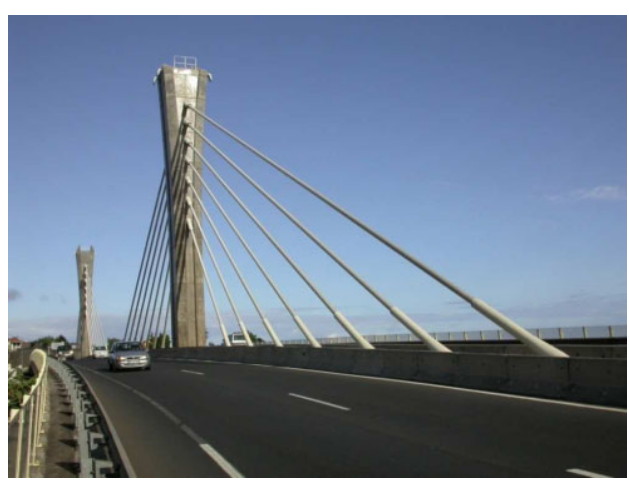

Figure 6. Viaduto do Comboio, Madeira Island 
Table 3. Study of the influence of EI on cable frequency

\begin{tabular}{|c|c|c|c|c|c|}
\hline \multirow[b]{2}{*}{$\begin{array}{c}\text { Mode } \\
\text { no. }\end{array}$} & \multicolumn{4}{|c|}{ Natural frequency $(\mathrm{Hz})$} & \multirow[b]{2}{*}{$(1) /(2)$} \\
\hline & $\begin{array}{c}\mathbf{E I}=\mathbf{0} \\
(1)\end{array}$ & $\begin{array}{c}\mathbf{E I}=\mathbf{3 1 .} \\
\mathbf{I}_{\text {st }}(2)\end{array}$ & Exp. & $\begin{array}{c}\mathbf{E I}=\mathbf{3 1} . \\
\mathbf{I}_{\text {st }} \\
\text { supp. } \\
(\mathbf{3})\end{array}$ & \\
\hline 1 & 4.229 & 4.2478 & 4.4434 & 4.4159 & 1.0044 \\
\hline 2 & 8.4577 & 8.4948 & 8.4277 & 8.8311 & 1.0044 \\
\hline 3 & 12.689 & 12.743 & 12.7539 & 13.248 & 1.0043 \\
\hline 4 & 16.924 & 16.993 & 16.8262 & 17.667 & 1.0040 \\
\hline \multicolumn{6}{|c|}{$\begin{aligned} \mathrm{L}=33.49 \mathrm{~m} ; \mathrm{m}=50.85 \mathrm{~kg} / \mathrm{m} ; \text { No. strands: } 37 ; \text { Area: } 51.8 \mathrm{~cm}^{2} ; \\
\mathrm{E}=196 . \mathrm{GPa} ; \mathbf{T}=\mathbf{4 0 8 0 k N} ; \varepsilon=4.0 \mathrm{e}-3\end{aligned}$} \\
\hline
\end{tabular}

But in fact there is an important uncertainty in the force assessment for these cables that relates to the definition of their fixed length. The length of the cables between anchorages is well defined, as well the free length of the cables, that is the length of the cables outside the guiding pipes (Fig. 6). These differ $11 \%$ to $17.5 \%$, if the former is taken as reference and could result in errors of force estimate of the order of $22 \%$ to $37.5 \%$. Iterative variations of the cable length have then been simulated in order to better approximate the measured frequencies. A pattern was however observed consisting in a first measured frequency systematically higher than the numerical and higher order frequencies systematically lower than corresponding numerical values for the matched force, for each length tested. It was concluded that neoprene guides inside the pipes could constrain vibrations and act as simple supports. The modelling of that condition, with results designated by (3) in Table 3, indicates that it is only valid for the first frequency (considering the highest contribution in terms of deformation). For higher order modes, the first condition should apply. In fact this type of behaviour has already been found in the testing of similar cables, as the temporary cables used in the construction of the Infante D. Henrique (Fig. 7), with lengths of $5 \mathrm{~m}$ to $47 \mathrm{~m}$. For these cases, the combination of numerical simulations with experimental data were determinant to reduce the error in the force estimation.

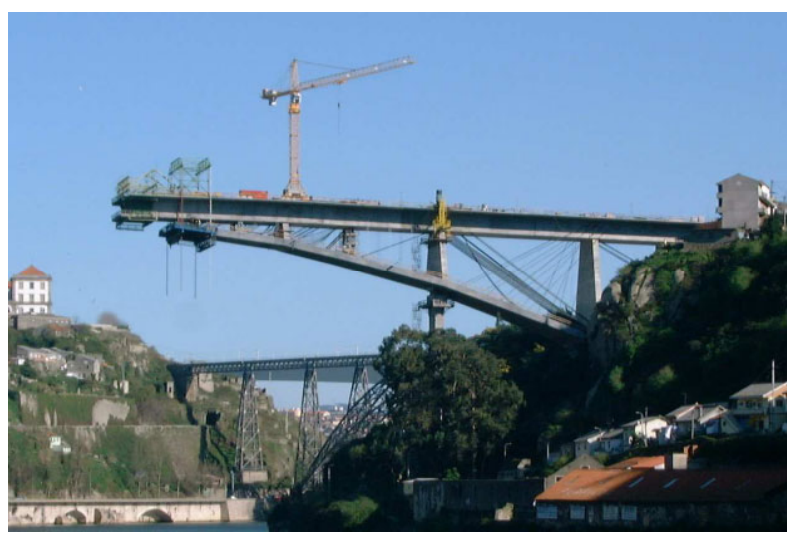

Figure 7. Infante D. Henrique Bridge: use of temporary cables as diagonals of truss during construction of the arch
Another example of assessment of force in short cables refers to the cables integrating the tension ring of the London 2012 stadium roof (Fig. 8). In this case, the clamps of the 10 cables forming the inner ring define spans of $5 \mathrm{~m}$ to $7 \mathrm{~m}$, whose length is well defined, but which end condition is not evident. Site testing using hammer excitation of the cables provided estimates of the most relevant vibrating frequencies. The mechanical characteristics of one of these cables are summarised in Table 2 and the identified first four frequencies are shown in Fig. 9. The strong deviation from linearity displayed evidences the relevance of bending stiffness effects, which need to be accounted in the assessment of cable force. In this respect, it is relevant to mention the application of both formula (2) and the formulation from Zui et al. [8], which provided similar values of the increased frequencies (with regard to the vibrating chord frequency) of $13 \%, 15 \%$ and $16 \%$ for the first, second and third cable modes, respectively, assuming the cable inertia equal to that of the solid section with identical diameter. However, finite element modelling of the cable led once more to lower increases of frequency of $3 \%, 8 \%$ and $13 \%$, respectively, independently of the support conditions. Therefore the latter values were used to assess cable force.

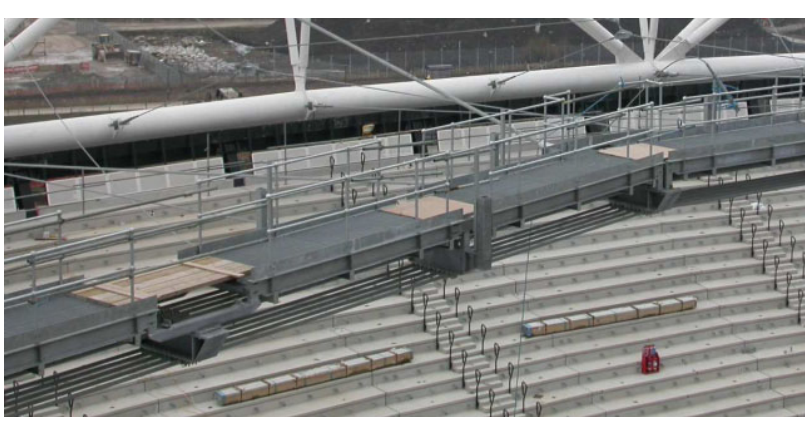

Figure 8. London 2012 Olympic stadium: tension ring

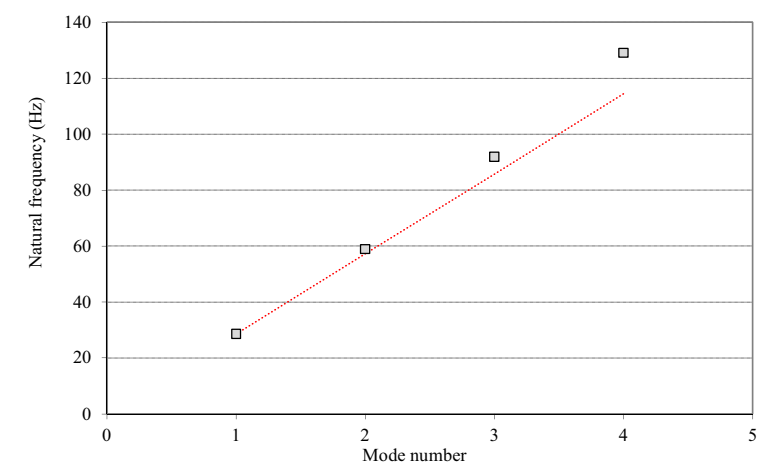

Figure 9. London 2012 Olympic stadium: natural frequency vs mode order for one cable from tension ring

But, even accounting for bending stiffness effects, in this case support conditions are the major cause of error in force estimation. The cable is clamped at the ends in an extension of $200 \mathrm{~mm}$ on one end, and $75 \mathrm{~mm}$ on the other. Furthermore, the tension ring on which it is supported is a flexible structure. These two issues were investigated. Considering the low amplitude of the local excitation, it 
is unlikely that the cable ends exhibit displacements, although rotations could result. Fig. 10 resumes the investigated support conditions based on the finite element modelling of the cable, considering the span defined by the end or the middle of the clamps, and preventing or not rotations on the two situations. The force of $1378 \mathrm{kN}$ was installed as reference. The fact that the measured vertical frequency was always slightly higher than lateral allowed concluding that support flexibility was not effective, therefore the simulations (5) and (6) in Fig. 10 were disregarded and only the simulations (1) to (4) in that figure were considered. These implied frequency variations of $-6 \%$ to $+12 \%$ of the one taken as reference, therefore leading to force estimation variations in the range $-12 \%$ to $+24 \%$. The most realistic situation should be somewhere between (1), (3) and (4), according to the results presented in Table 4. These provide a narrower force estimation error of $-12 \%$ to $+10 \%$. By choosing the reference simple support situation between clamps $(\mathrm{L}=5.151 \mathrm{~m})$, it was observed that the resulting force estimates were very close to those provided by the manufacturer. Nevertheless the incertitude of $-12 \%$ to $+10 \%$ should be added to the final force estimates.
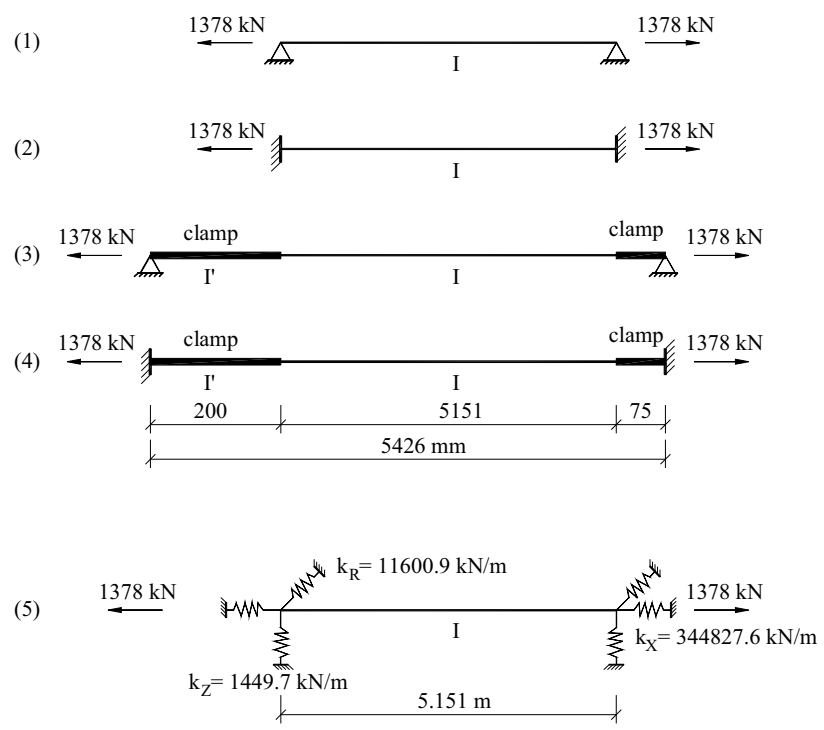

(6)

$$
\mathrm{k}_{\mathrm{X}}, \mathrm{k}_{\mathrm{Z}}, \mathrm{k}_{\mathrm{R}} \times 10
$$

Figure 10. London 2012 Olympic stadium: investigation of tension ring bay support conditions

Table 4. Investigation of possible support conditions for tension ring cable at the London 2012 Olympic stadium roof

\begin{tabular}{|c|c|c|c|c|}
\hline \multicolumn{5}{|c|}{ Frequency for model (Hz) } \\
\hline Exp. & (1) & (2) & (3) & (4) \\
\hline $\mathbf{2 8 . 2 0 3 1}$ & 27.85 & 31.133 & 26.404 & 29.342 \\
\hline $\mathbf{5 7 . 9 6 8 8}$ & 57.879 & 64.678 & 54.677 & 60.748 \\
\hline $\mathbf{9 1 . 1 3 2 8}$ & 92.003 & 102.66 & 86.486 & 98.981 \\
\hline $\begin{array}{c}\text { Average } \\
\text { increase/ } \\
\text { decrease }\end{array}$ & Reference & $+12 \%$ & $-6 \%$ & $+5 \%$ \\
\hline
\end{tabular}

\begin{tabular}{|c|c|c|}
\hline \multirow{2}{*}{ Freq. } & \multicolumn{2}{|c|}{ Frequency for $\operatorname{model}(\mathbf{H z})$} \\
\cline { 2 - 3 } & $\mathbf{( 5 )}$ & $\mathbf{( 6 )}$ \\
\hline F1z & 20.408 & 26.348 \\
\hline F1y & 26.334 & 27.734 \\
\hline F2 & 43.152 & 55.638 \\
\hline F2y & 54.584 & 57.614 \\
\hline F3 & 69.658 & 88.008 \\
\hline F3y & 86.347 & 91.520 \\
\hline
\end{tabular}

Despite the significant uncertainty in force estimation for so short cables, the conducted measurements were of interest in order to compare the force installed in the 10 cables forming the tension ring and gave valuable information in order to increase the uniformity of force distribution. The estimates of force obtained for the 10 identical cables of the same bay are shown in Fig. 11.

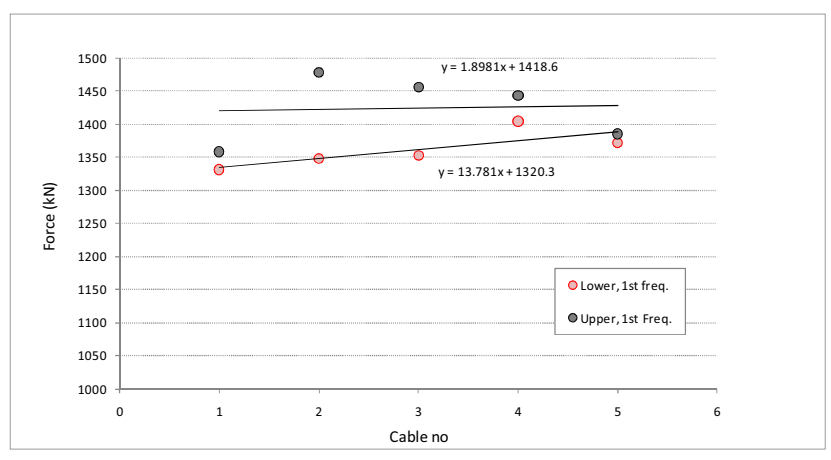

Figure 11. London 2012 Olympic stadium roof: estimates of force on the 10 individual cables of the tension ring

It was demonstrated in the previous application that the combination of experimental measurements with numerical simulations could be used in order to assess both sag and bending effects, and also to analyse the support conditions framing the real cable behavior. In fact, both the mentioned and other existing formulations for identification of cable force are based on the fitting of some formula expressing some previous assumption of the support conditions of the cable. Applications in roof structures, in which cables are actually part of flexible networks show that support conditions can considerably differ from the hinge and clamp. Furthermore, the relatively short cable length and the non-negligible stiffness of the anchorages contribute to enhance the errors resulting from the incorrect identification of these conditions. It is therefore extremely important to incorporate the support condition as part of the identification process, in parallel with the force and mechanical properties of the cables, namely the bending stiffness EI. To illustrate this procedure, mention is made to the identification of force in the radial cables of the London 2012 Olympic stadium roof (Fig.12), considering as an example a cable with the characteristics indicated in Fig. 13.

Fig. 14 represents the various idealisations tested for the same installed force of $1854 \mathrm{kN}$, while the results of a modal analysis are summarised in Table 5. In all cases a mesh of 40 beam elements was used, with the inertia of 
the solid section of the cable. Increased area and inertia of end elements was used for models (1), (2) and (4) of Fig. 14 , in order to simulate the mass and stiffness of the sockets. As shown in Table 5, framing conditions for the natural frequencies of the cable are full pinned ends (1) or clamping at the cable ends (2). An intermediate case was considered of the pinned cable between the sockets (3). For that situation, natural frequencies are calculated assuming also zero bending stiffness and zero sag. In the model (4) an intermediate support condition was tested by introduction of a rotational restraint at the anchorages, defined by a constant $\mathrm{K}$. This constant was identified iteratively by adjustment of the FE model in order to fit the measured natural frequencies represented in the last column of Table 5 and the corresponding mode shapes.

The ratios between natural frequencies calculated for the different support conditions and the natural frequencies of a simply supported non-sagged cable (5) are shown in Table 5 . The analysis of these ratios for the two framing support conditions (1) and (2) shows that the use of the vibrating chord formula would lead to force estimates defined with confidence in a $20 \%$ to $30 \%$ interval of variation. Considering the interval of variation of natural frequencies in the framing conditions (1) and (2), the choice of the support condition (4) would provide an error in the force estimate of $10 \%$ to $15 \%$. In order to reduce this uncertainty, it was decided to conduct an additional test which consisted in identifying the mode shape configurations of a cable, using them to fit the rotational spring constant at the anchorages of the cable (Fig. 14, model (4)). Such exercise led to the identification of a stiffness constant of $4000000 \mathrm{~N} / \mathrm{rad}$. The identified mode shape components fit extremely well the simulation of the first four vibration modes using this constant as represented in Fig. 15 for two of the vibration modes. The natural frequencies calculated using end springs are then taken as reference. The ratios of these frequencies to those of the baseline model constitute the correction coefficients to reduce all tested cables to equivalent baseline cables to which the vibrating chord theory applies. Therefore the procedure to identify the installed cable force for all cables with identical characteristics consists in dividing the measured frequencies by the derived correction factors and then applying the vibrating chord formula to the set of measured natural frequencies.

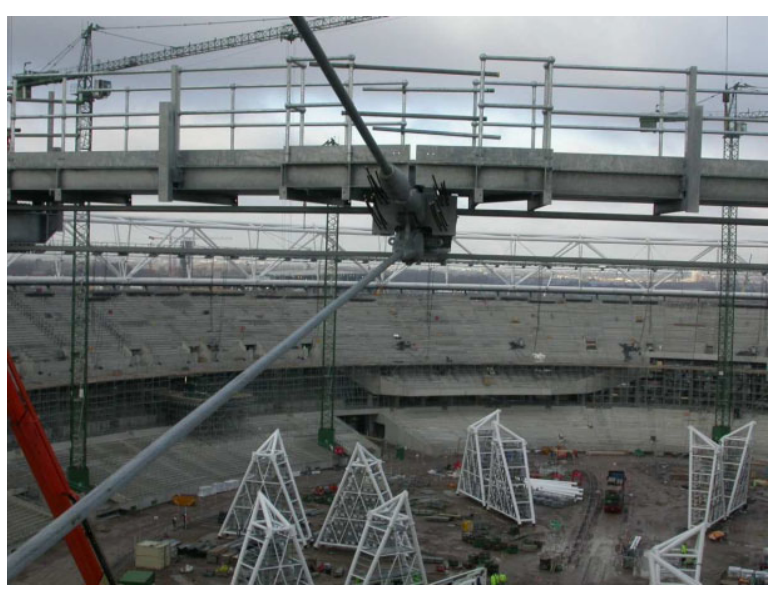

Figure 12. London 2012 Olympic stadium roof: radial cables supporting the tension ring

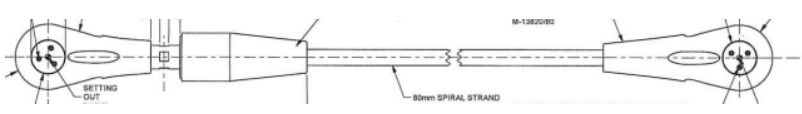

Diameter: $80 \mathrm{~mm}$; Mass: $30.8 \mathrm{~kg} / \mathrm{m}$; Area: $36.7 \mathrm{~cm}^{2}$;

$$
\mathrm{E}=155 \mathrm{GP} ; \mathrm{I}=201 \mathrm{~cm}^{4}
$$

Figure 13. Characteristics of radial cable from the London 2012 Olympic stadium roof

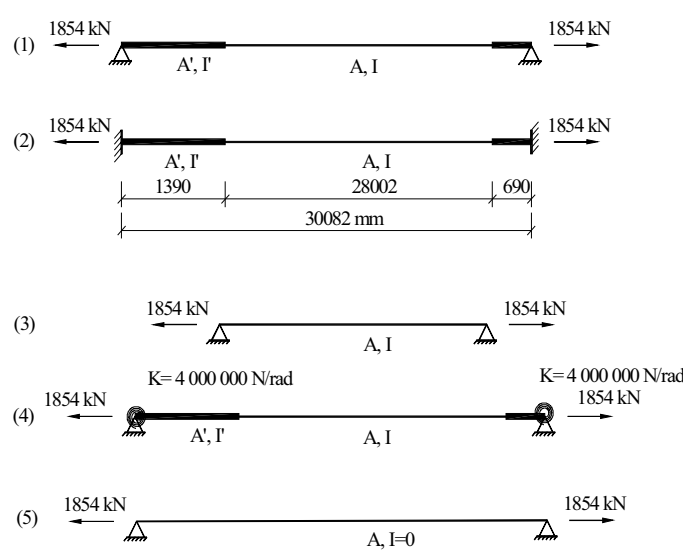

Figure 14. Investigated support conditions of one radial cable from the London 2012 Olympic stadium roof

Table 5. Natural frequencies of radial cable from the London 2012 Olympic stadium roof, calculated and measured

\begin{tabular}{|c|c|c|c|c|c|c|c|}
\hline \multirow[b]{2}{*}{ Freq. (Hz) } & \multicolumn{6}{|c|}{ Model } & \multirow[b]{2}{*}{ Measured } \\
\hline & $\begin{array}{c}(1) \\
I '=50 \text { I }\end{array}$ & $\begin{array}{c}(2) \\
I '=50 \text { I }\end{array}$ & (3) & (4) & $\begin{array}{c}\text { (3) } \\
I=0 . \text { sag }=0\end{array}$ & (5) & \\
\hline F1 & 4.0718 & 4.4328 & 4.3877 & 4.297 & 4.3689 & 4.0784 & 4.2969 \\
\hline F2 & 8.0848 & 8.8869 & 8.8007 & 8.5908 & 8.7377 & 8.1568 & 8.5442 \\
\hline F3 & 11.964 & 13.387 & 13.27 & 12.871 & 13.107 & 12.2352 & 12.8869 \\
\hline \multirow[t]{2}{*}{$\mathrm{F} 4$} & 15.666 & 17.953 & 17.82 & 17.093 & 17.475 & 16.3136 & 17.1777 \\
\hline & & & & Reference & & Baseline & \\
\hline F1/F1 (5) & 0.998 & 1.087 & 1.021 & 1.054 & 1.017 & 1.000 & \\
\hline F2/F2(5) & 0.991 & 1.090 & 1.024 & 1.053 & 1.017 & 1.000 & \\
\hline F3/F3(5) & 0.978 & 1.094 & 1.031 & 1.052 & 1.018 & 1.000 & \\
\hline F4/F4(5) & 0.960 & 1.100 & 1.043 & 1.048 & 1.022 & 1.000 & \\
\hline
\end{tabular}



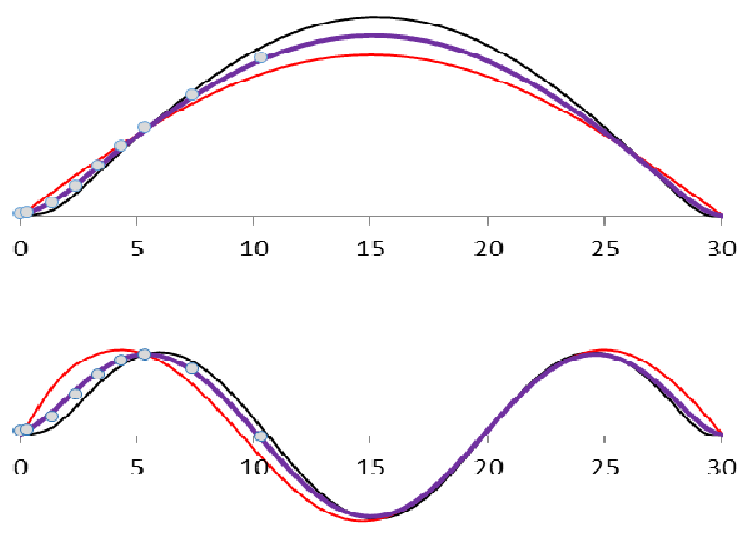

Cable length $(\mathrm{m})$

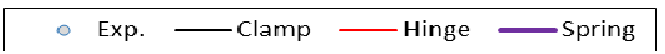

Figure 15. Identified and calculated modal components for London 2012 Olympic stadium roof cable modes 1 and 3

A final example regarding the identification of cable force is shown for a very low tensioned cable, in this case integrated in a guyed mast with a height of $265 \mathrm{~m}$ (Fig. 16).

The Muge antenna represented in Fig. 16 is formed by a steel truss with a square plant supported at 7 levels by a total of 28 cables arranged in two orthogonal plans. These cables have lengths of $72 \mathrm{~m}$ to $313 \mathrm{~m}$ and diameters of 17 $\mathrm{mm}$ to $24 \mathrm{~mm}$. Considering the design tension of these cables, the Irvine parameter would range from 1 to 12 , for the shortest and longest cables, respectively, meaning the behavior as slack and sagged cables. Cable frequencies measured with the interferometric radar are systematized in Fig. 17 and evidence this behavior.

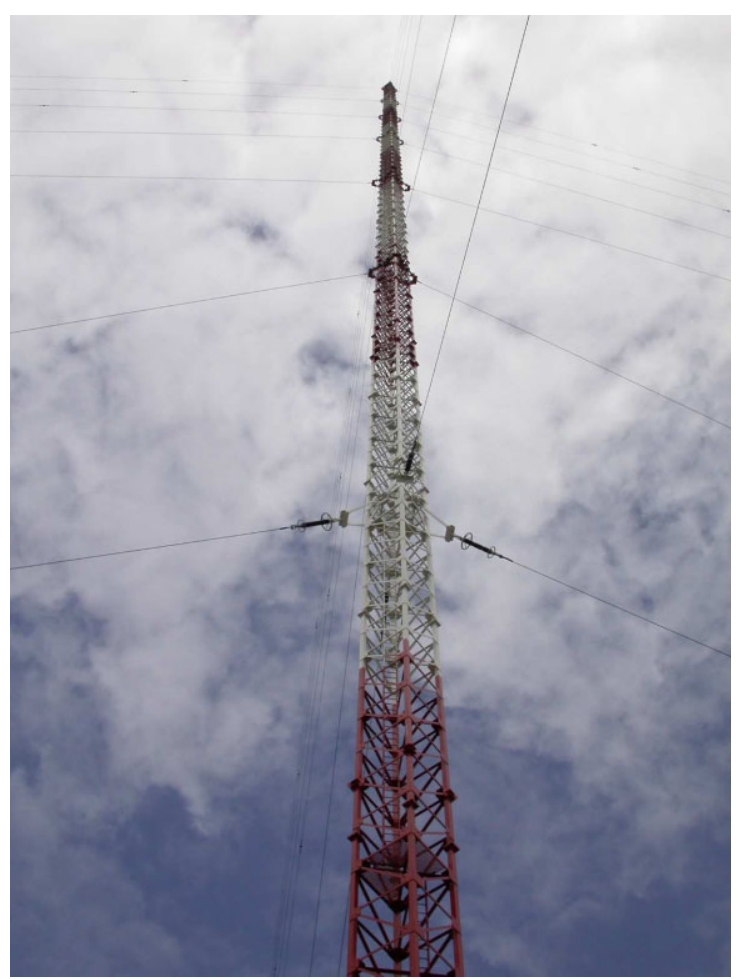

Figure 16. Partial view of Muge antenna

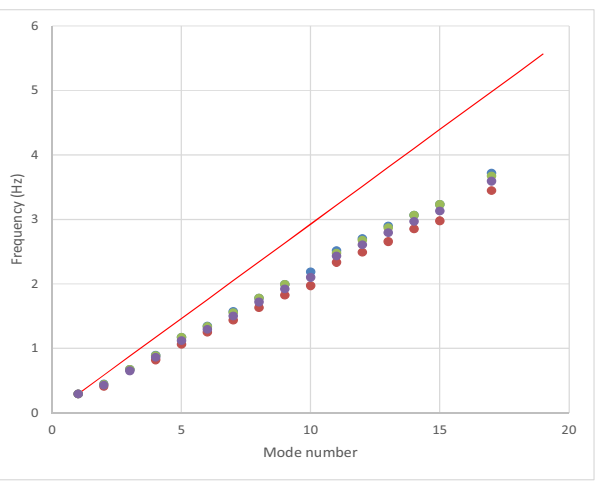

Figure 17. Identified natural frequencies for the four longest cables of the Muge antenna

The identification of force using the simplified formulae (4) fitted to the first identified frequency would indicate a sagged frequency increase of $44 \%$ with regard to the vibrating chord, and an estimate of an installed force of $42 \mathrm{kN}$. However, the numerical modelling of the cable by means of a discretization in truss elements and assuming simple support conditions at both ends of the cable, would provide a set of natural frequencies deviating strongly from the measured frequencies with the increase of the mode order, as shown in Fig. 18. The more flexible behavior of the instrumented cable is in this case motivated by the flexible support on the antenna, which stiffness should be identified together with the cable force. In the present case, a stiffness constant of $40000 \mathrm{~N} / \mathrm{m}$ at the top of the antenna was identified, together with an installed force of $32 \mathrm{kN}$, instead of the $42 \mathrm{kN}$ that would be estimated if the wrong support conditions were considered.

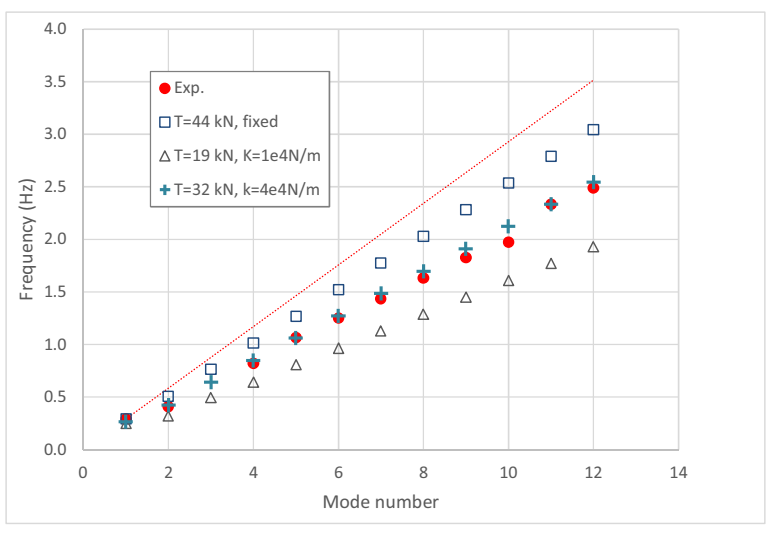

Figure 18. Identified natural frequencies for the four longest cables of the Muge antenna.

\section{Assessment of damping and vibrations}

Low damping is characteristic of most cable structures. Depending on the length, cable and anchorage type, the structural damping ratio of a cable can vary from values as low as $0.04 \%$ to more than $1 \%$, according to the author's experience. The identification of cable damping is therefore of utmost importance in the assessment of vibration levels and in the definition of mitigation measures. In order to obtain sufficient accuracy, free vibration tests are normally required during which cables 
are manually or mechanically excited to resonance. For long span cables excitation is more effective at a sufficient distance from the cable anchorage, especially when dampers are already installed. This is exemplified in Fig. 19 for the Arade Bridge cable tests [18], in which a crane was used to manually excite the cables at a height of about $10 \mathrm{~m}$. Both this bridge and the Guadiana Bridge previously mentioned were constructed at the same time, in 1991, and employ the same cable system, a bundle of individually protected strands not encased in a pipe. A comparison of damping ratio estimates for the two bridges is presented in Fig. 20. A trend for higher damping ratios is generally observed for identical length cables at the Arade Bridge, which has also a shorter main $\operatorname{span}(256 \mathrm{~m})$.

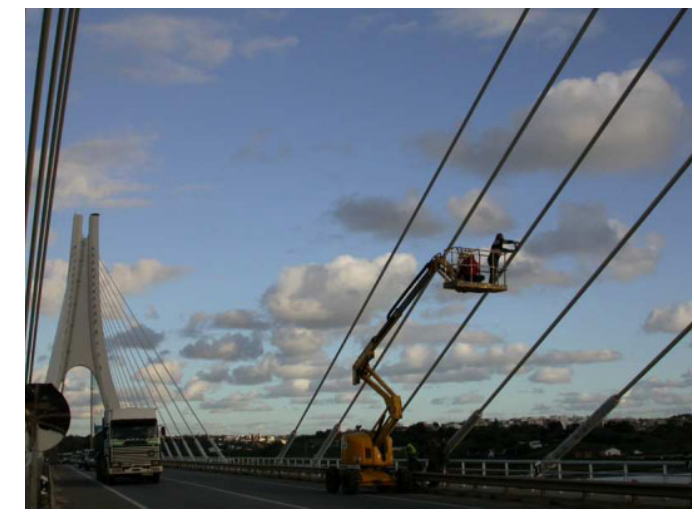

Figure 19. Manual excitation of cables to resonance for identification of cable damping at the Arade Bridge

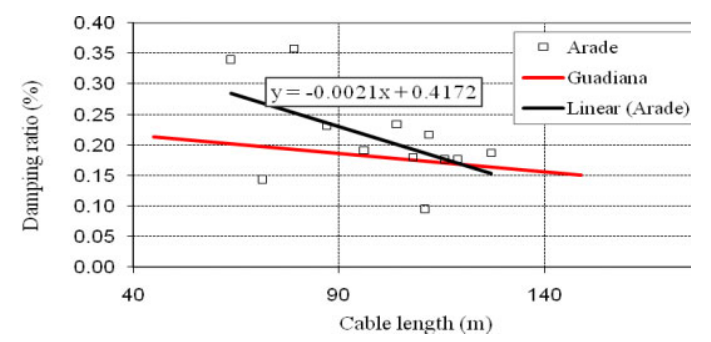

Figure 20. Variation of identified damping ratios with cable length at the Arade and Guadiana bridges

It should be pointed however that the structural damping is strongly dependent on the amplitude of cable vibrations. This is very relevant in cable roof structures, given that cables have normally a smaller diameter and are easier to excite, reaching very high amplitude vibrations.

The very low damping ratios of cables, combined with a considerable flexibility, result in a significant proneness to vibrations induced by wind and other resonant actions. It is relevant to mention that, considering the relatively low design stress, large cable vibrations do not generally lead to significantly relevant amplitudes of cyclic variation of axial stress and, in theory, these would not pose fatigue problems. However, bending effects close to the anchorages may cause local damage and contribute to reduce the durability of cables.

Vibrations in cables from cable-stayed bridges are the most widely reported, although fatigue problems in overhead transmission associated with cable vibrations are also frequent. Despite the immense research conducted in the last decades on the various phenomena behind cable vibrations, which have allowed to identify triggering conditions and develop formulations for the analysis of the various phenomena, as rain-wind induced vibrations, galloping, vortex-resonance, interference effects and parametric excitation, no integrated approach for the design of cables has passed into recommendations and standards until now. This is due to the fact that the various phenomena are in fact complex, but also to the difficulty in their assessment on site.

Considering as an example a cable-stayed bridge, the characterisation of cable vibrations implies the identification of cables experiencing vibrations, the evaluation of their amplitude and the identification of the triggering conditions for vibration events. In order to have a full picture of the cable-stayed bridge behaviour, all stay cables should be monitored. Deck and towers' vibration should also be monitored, with the purpose of detecting possible cable-structure interaction. Finally, wind characteristics and rainfall are complementary measures of high importance.

The dimension and cost of a monitoring system able to perform all the ideal measurements make it impossible to achieve in most circumstances. In fact, most of the monitoring systems installed with the purpose of characterising cable vibrations are partial and focus on a small number of sensors, addressing particular effects that have been previously captured through individual measurement and inspection campaigns.

In the case of the Guadiana Bridge, several measurement campaigns allowed the observation of almost systematic vibrations in almost all the cables, which are clearly started by wind. Several episodes of high amplitude of vibration of specific cables have also been observed, either under moderate wind, or else under almost no wind. It is relevant to mention that in most of the observed circumstances the same cables vibrated, which were generally amongst the six longest cables of the central span, and some intermediate cables of one side span. This was in fact consistent with small nonstructural damage observed on these cables, caused by the loss of cable ties and the damage of the neoprene rings inside the deviator guides at the deck anchorages. The additional information that these cables have natural frequencies very close to some important bridge frequencies suggested the presence of strong cablestructure interaction which could be of parametric type. So these cables and the deck were simultaneously instrumented using accelerometers and sporadic observations were conducted [19]. In order to have a better characterisation of the starting condition and duration of vibration events, it was considered of interest to install a permanent monitoring system on the bridge. The mounting of accelerometers on the many vibrating cables would be extremely onerous, therefore a different strategy was considered, which consisted in using a video camera and image processing in order to be able to simultaneously measure vibrations in many cables.

Optical instrumentation has many limitations, in particular those referring to the accuracy and frequency 
resolution. But cables vibrate with high amplitudes and the most critical frequencies are in general within the reach of modern video cameras. Therefore a vision system was constructed and tested for observation of cables. The camera and acquisition system were installed in a building located about $850 \mathrm{~m}$ from the bridge (Figure 21).

Continuous measurements were conducted during several months, in the period 9h00-16h00. In those periods, and using the optical flow method, velocity time series associated to a set of pre-selected points were formed, which were subsequently integrated, rotated and scaled in order to provide the temporal variation of displacements. Fig. 22 shows the daily variation of maximum 20-min amplitude observed in a set of stay cables. This allows the detection of episodes of cables vibrations, characterising the corresponding duration and the correlation with direction and wind velocity, according to information provided by a local meteorological station [20].
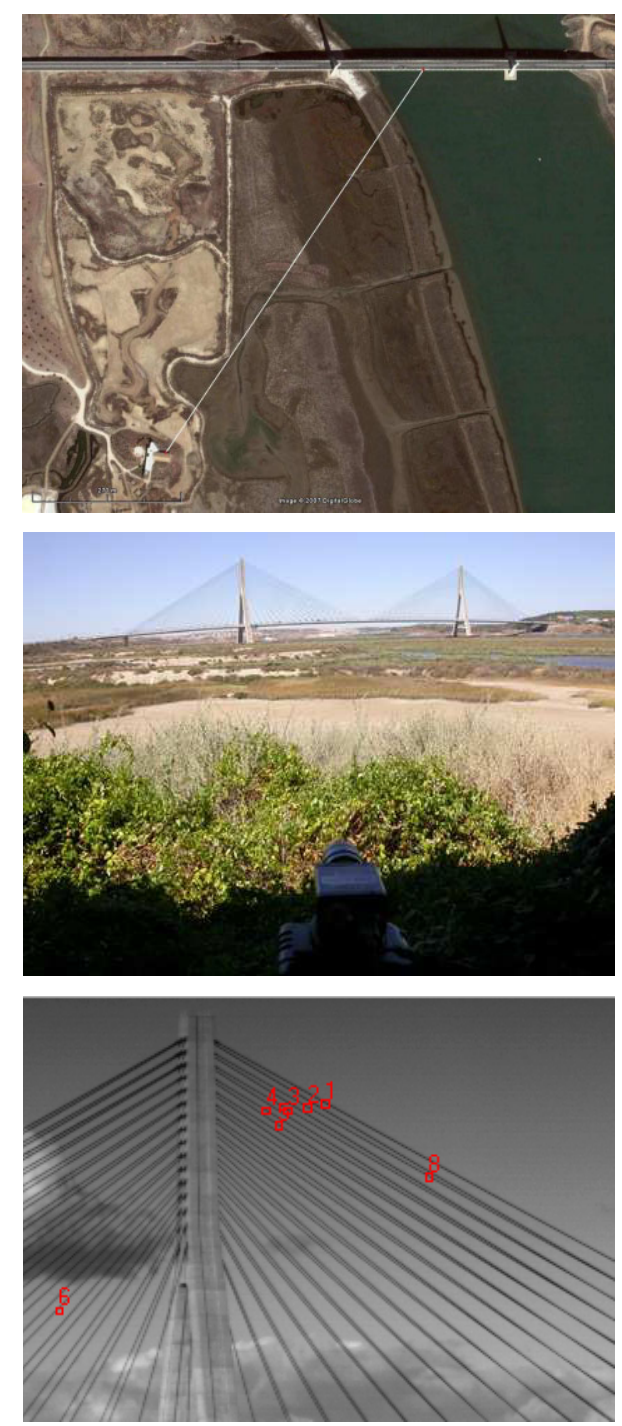

Figure 21. Application of the vision system to the dynamic monitoring of the Guadiana Bridge. Location of the video camera and selection of measurement points.

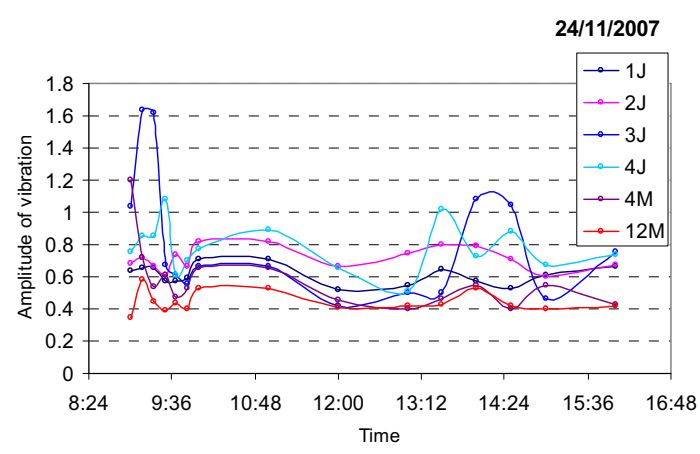

Figure 22. Envelope of response of 6 stay cables monitored with the vision system in the period $9 \mathrm{~h}-16 \mathrm{~h}$.

A second example regarding the assessment of cable vibrations respects an overhead transmission line. The fact that these structures operate in tension poses an important limitation to the assessment of vibrations from field measurements. The existence of a non-powered line to be de-activated in the vicinity of Porto created the opportunity to introduce a temporary monitoring system based on a set of accelerometers, fibre optic strain gages and on one anemometer, according to the scheme of Fig. 23. This system has been partially installed and simultaneous records of acceleration are being collected on the top of the tower and at two sections of the conductor. Fig. 24 shows the power spectra density functions of two records registered under very low mean wind velocity of $3 \mathrm{~m} / \mathrm{s}$, corresponding to longitudinal measurements at the top of the tower and vertical accelerations of the conductor at a distance of $10 \mathrm{~m}$ from the tower. It is curious to note that four relevant frequency peaks are evident in the response of both the tower and the conductor at high frequencies of vibration, which could well be identified as Aeolian vibrations. With the increase of wind velocity to $4.9 \mathrm{~m} / \mathrm{s}$, both the tower and conductor responses increase, but the four marked peaks in the conductor and tower response disappear, indicating apparently a more favourable behaviour of the conductor. This issue requires evaluation and correlation with wind properties for a wider range of velocities.

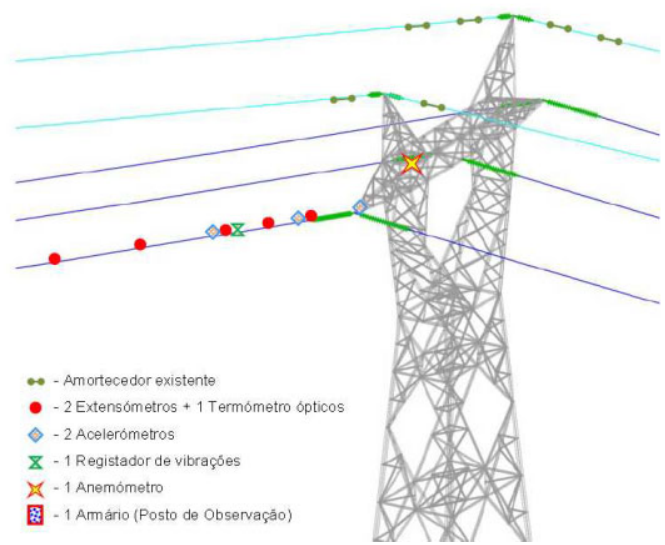

Figure 23. Monitoring system of overhead transmission line in Santo Tirso, Portugal 


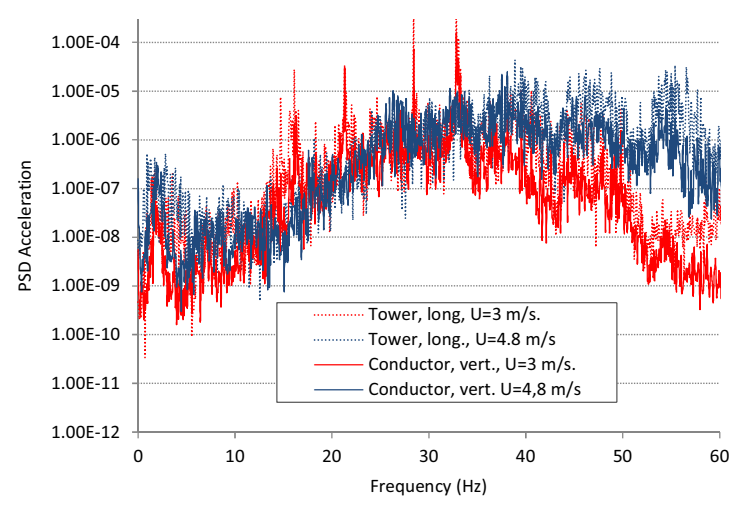

Figure 24. Overhead transmission line in Santo Tirso, Portugal: PSD of acceleration at tower and conductor

\section{Dynamic monitoring}

The proneness of cable structures to vibrations and the frequent observation of a reduced service life of these structures and members have motivated the interest in assessing the corresponding structural condition by means of the permanent dynamic monitoring. More than any other type of structure, suspension and cable-stayed bridges have been the object of dedicated monitoring systems, enabling the permanent characterisation of the response and the automatic identification of modal parameters, from which variation damage can be identified at early stages. The necessity to control the geometry and pre-stress, as well as the need to assess vibrations, damping and environmental factors on the structural behaviour and geometry are posed with more acuity in cable roofs, although the practice in the monitoring of these structures has not been sufficiently disseminated. In this respect, mention is made to the cable roof of the Braga Municipal stadium (Fig. 25), composed by 34 pairs of full locked coil cables spanning $202 \mathrm{~m}$ between the tops of two opposite tribunes, supporting two slabs over the latter on the first $57.3 \mathrm{~m}$ in each end, the central $88.4 \mathrm{~m}$ being free. The unusual structural system motivated the installation of static, dynamic and wind monitoring systems during construction [21].

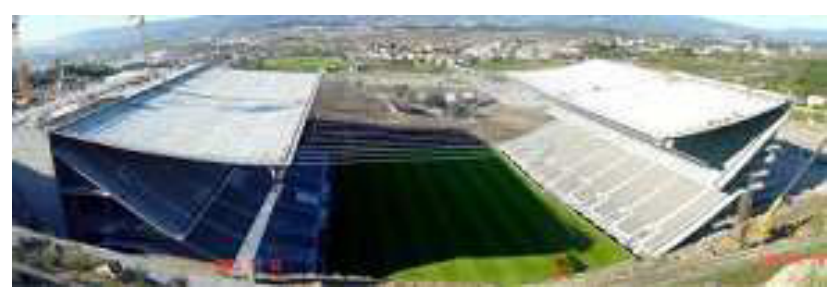

Figure 25. View of Braga stadium cable roof

With the purpose of investigating the sensitivity of the structure to ambient effects and wind, ViBest/FEUP installed two complementary monitoring systems on the west concrete slab: one to measure the dynamic response and other to collect wind and temperature data [22]. The dynamic monitoring system, composed by six accelerometers, allows the characterisation of the amplitudes of vibration of the slab, as well as the permanent identification of natural frequencies, modal shapes and modal damping ratios. The wind monitoring system, composed by two three-dimensional ultrasonic anemometers is synchronised with the dynamic monitoring system by accurate internal clocks set by GPS and allows the characterisation of wind loads and the correlation of the roof response with the wind velocity.

The monitoring system provides information at different levels, the first being the characterisation of the vibration amplitude under wind excitation. The analysis of the plots presented in Fig. 26 of the peak and the RMS (root mean square) of the acceleration measured during the first 50 days of operation of the monitoring system evidences the generally very low level of vibration. During the night, RMS values of acceleration are normally lower than $50 \mu \mathrm{g}$. These values increase to around $300 \mu \mathrm{g}$ during day light. Higher vibrations are observed on weekends (e.g. $28,29^{\text {th }}$ March), probably due to events in the stadium or in the surroundings.

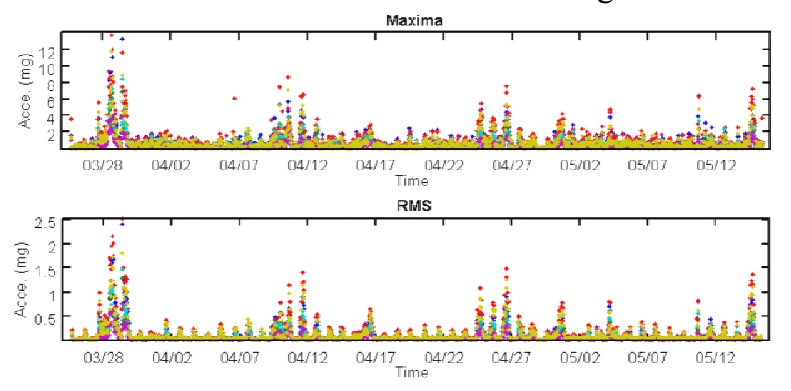

Figure 26. Evolution of acceleration levels in the period from $2009 / 03 / 25$ to $2009 / 05 / 15$

In a second level, automatic identification of the modal parameters (natural frequencies, mode shapes and damping ratios) is performed based on the continuously measured ambient vibration response. For this purpose, the developed algorithms process 60-minute acceleration files using the Covariance driven Stochastic Subspace Identification method (SSI-COV), complemented with a methodology based on the hierarchical clustering algorithm to automatically interpret stabilisation diagrams [23]. It is mentioned that initial ambient vibration tests allowed the accurate identification of the most relevant vibration modes [24], which have been taken as baseline for the purpose of automatic identification. Examples of identified vibration modes are shown in Fig. 27 and a list of the natural frequencies and damping ratios of the modes with frequency lower than $1 \mathrm{~Hz}$ is presented in Table 6 .

Referring to results of the automatic modal identification, Fig. 28 shows the evolution of the 12 identified natural frequencies of the roof structure in the range $0.1-1.1 \mathrm{~Hz}$ since the installation of the wind measurements system, in December 2011, until the first days of August 2012. A sample of nine days evolution of natural frequencies from modes 3,4 and 5 is presented in Fig. 29 (b), corresponding to the mean wind speed and temperature variations represented in Fig. 29 (a). Here, a daily variation effect of environmental (temperature and wind) and operational (activities in the vicinity of the stadium) factors, can be observed for each mode. It is 
interesting to note that temperature and wind can affect differently the different modes: evolution of the natural frequencies of $3^{\text {rd }}$ and $4^{\text {th }}$ modes is contrary to the $5^{\text {th }}$ mode. Representation of the corresponding modal configurations is shown in Fig. 27.

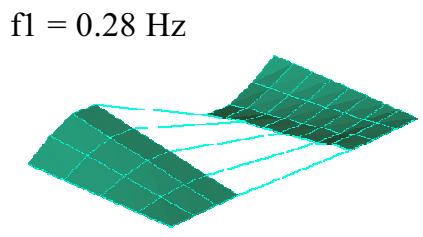

$$
\mathrm{f} 3=0.52 \mathrm{~Hz}
$$

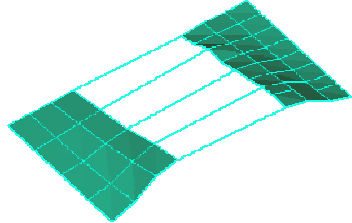

$\mathrm{f} 4=0.54 \mathrm{~Hz}$

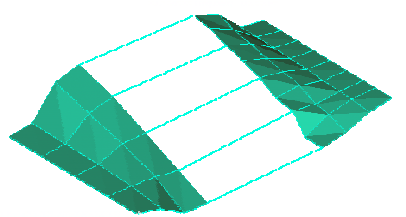

$\mathrm{f} 5=0.56 \mathrm{~Hz}$

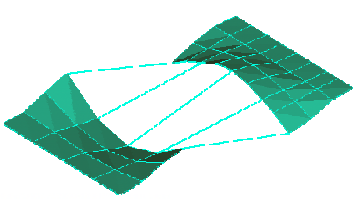

$\mathrm{f} 6=0.63 \mathrm{~Hz}$

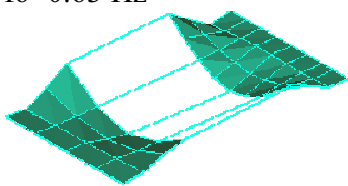

f1 $1=0.87 \mathrm{~Hz}$

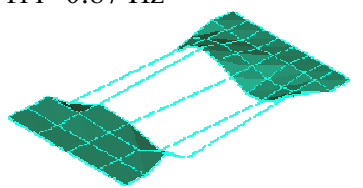

Figure 27. Examples of identified modes at Braga roof.

Table 6. Summary of natural frequencies and damping ratios at Braga roof (baseline test)

\begin{tabular}{|c|c|c|}
\hline Mode no. & $\begin{array}{c}\text { Frequency } \\
(\mathbf{H z})\end{array}$ & $\begin{array}{c}\text { Identified } \\
\text { damping ratio (\%) }\end{array}$ \\
\hline 1 & 0.275 & 0.28 \\
\hline 2 & 0.293 & 0.27 \\
\hline 3 & 0.525 & 0.22 \\
\hline 4 & 0.537 & 0.33 \\
\hline 5 & 0.562 & 0.53 \\
\hline 6 & 0.635 & 0.43 \\
\hline 7 & 0.653 & 0.29 \\
\hline 8 & 0.684 & 0.20 \\
\hline 9 & 0.702 & 0.18 \\
\hline 10 & 0.737 & 0.18 \\
\hline 11 & 0.874 & 0.38 \\
\hline
\end{tabular}

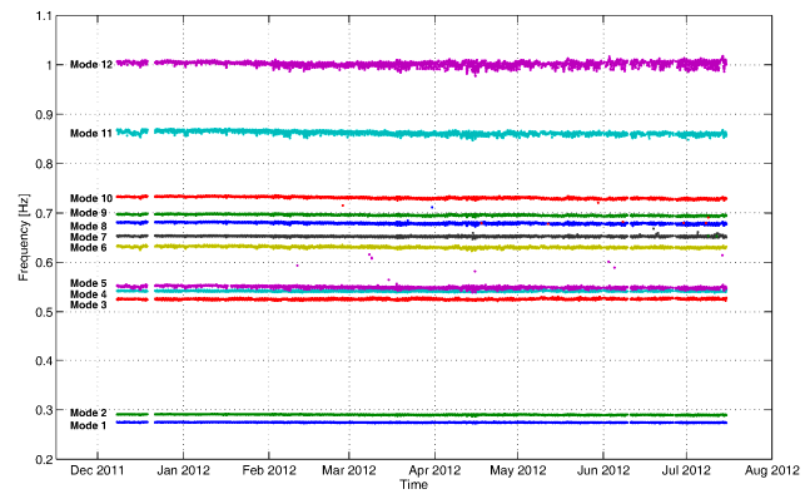

Figure 28. Braga stadium roof: time evolution of 12 first natural frequencies from December 2011 to August 2012

Fig. 29 (c) represents the variation of the damping ratio correspondent to modes 3,4 and 5 during the same period of nine days shown. Contrary to the well-defined evolution of natural frequencies, modal damping ratios exhibit significant scatter. This is not only due to the higher uncertainty associated with the estimation of these parameters, but also to the significant dependence on other variables, like wind and vibration amplitude. Nevertheless, a faint daily pattern can be observed, outcome of temperature and wind speed variation. Fig. 30 characterises, resorting to histograms, the dominant values and variability of the identified modal damping ratios during the period of eight months. The analysis of this figure evidences the generally very low damping ratios, which were also patent in the initial free vibration tests (Table 6).

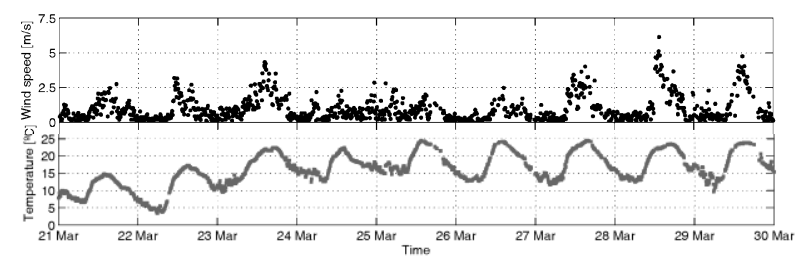

(a)

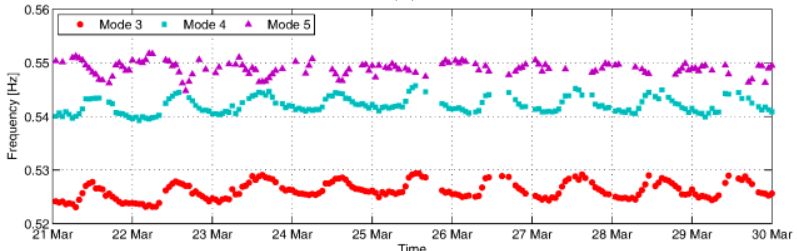

(b)

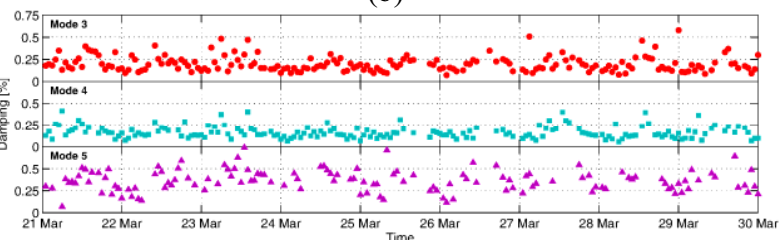

(c)

Figure 29. Time evolution from 21/03/2012 to 30/03/2012 of: (a) wind speed and temperature; (b) natural frequencies of modes 3, 4 and 5; (c) damping ratios of modes 3, 4 and 5 during the same period.

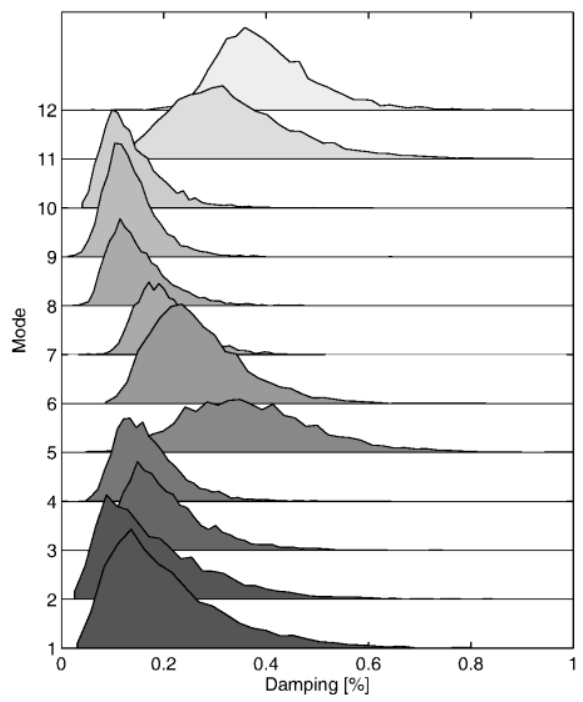

Figure 30. Dispersion of the identified modal damping ratios for the 12 first modes. 
The modal parameters identified by the dynamic monitoring system reflect the influence of environmental and operational factors. Of the various possible factors, temperature and wind have been identified as the ones that have a dominant role. To understand the corresponding effect, it is noted that temperature increase leads to a decrease of the elasticity modulus of the concrete of the slabs, to an increase of the cables length, and so, to an increment of the sag of the cables and reduction of tension, simultaneously with an increase of the slab bending stiffness. The combination of the two effects may result in increasing or decreasing frequency with temperature for different vibration modes, depending on the relative participation of slab bending and cable deformation. As for wind effects, positive incidence typical from Northern directions leads to a sag reduction, with consequent reduction of the cable tension and, possibly, frequency, while negative incidence, typical from Southern directions has an opposite effect .

In order to analyse the dependence between the mean wind speed, the ambient temperature variation and the value of the identified natural frequencies, the Pearson correlation coefficients were computed. Fig. 31 represents the variation of the identified frequency with temperature and the mean wind speed for the two vibration modes exhibiting the highest correlations: mode 3 (see Fig. 27), for temperature, and mode 11 (see Fig. 27), for wind speed. The completely different behavior shown by the two vibration modes illustrates the complexity of the problem.
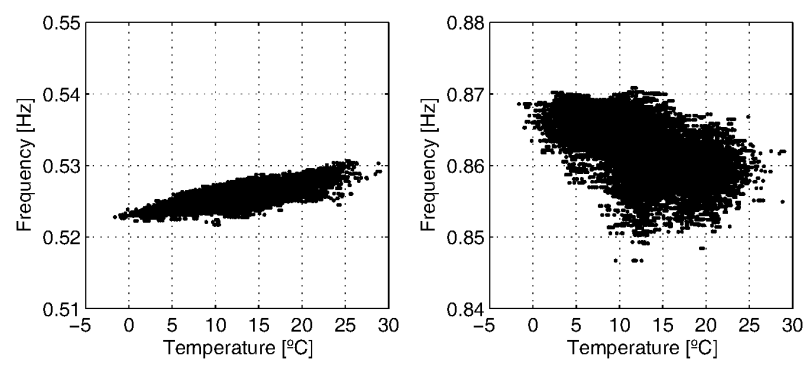

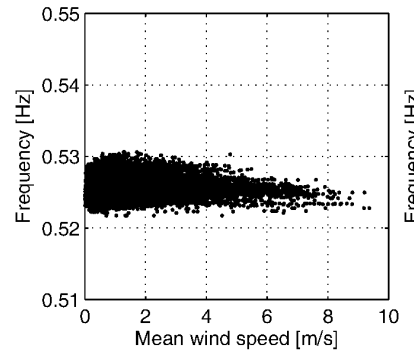

Mode 3

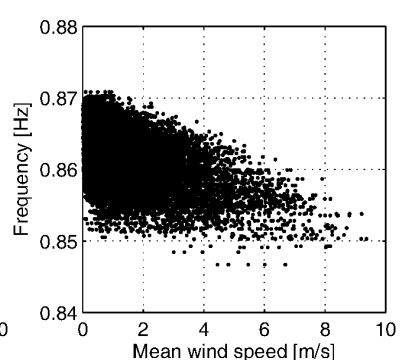

Mode 11
Figure 31. Correlation between the identified frequencies and the temperature and mean wind speed for modes 3 and 11

Referring to the damping ratio, an identical exercise was done in terms of evaluating the correlation with wind and temperature. It was concluded that, despite the low wind velocities measured, it is undoubtedly the wind velocity that better correlates with damping ratio, the highest correlations being achieved for the two modes represented in Fig. 32. The dot represented in the plots of this figure has been obtained from the average of the damping measurements corresponding to periods of very low wind speeds (lower than $2 \mathrm{~m} / \mathrm{s}$ ) and constitutes an estimate of the structural damping $\left(\xi_{\text {structural }}\right)$. The leastsquares linear fit was applied to the identified damping points associated with mean wind speed higher than $2 \mathrm{~m} / \mathrm{s}$. The constant term of the fitted line provides alternatively an estimate of the structural damping, while the slope parameter expresses the wind induced added damping gradient $\left(\Delta \xi_{\text {aerodynamic }}\right)[25]$.

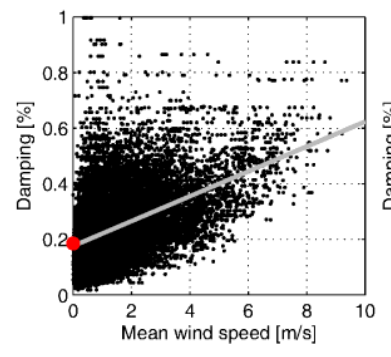

Mode 1

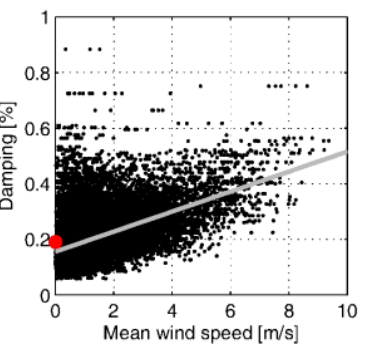

Mode 3
Figure 32. Correlation between the identified damping ratio and the mean wind speed for modes 1 and 3

Finally, the influence of wind speed on the structural response is described by the relationship between the 10min root-mean-square (RMS) acceleration response and the mean wind speed and direction for the same period of time. The vertical acceleration response measured by the six accelerometers of the monitoring system was analysed for periods of time in which the 10-min mean wind speed measured were greater than $4 \mathrm{~m} / \mathrm{s}$. Furthermore, the analysis took into account the 10-min mean wind direction, dividing acceleration responses according to sixteen $22.5^{\circ}$ directional sectors.

Fig. 33 shows the relationship between the mean wind speed and the vertical RMS accelerations measured by one of the accelerometers according to the three dominant wind directions. From the performed analysis only the three directional sectors between $315^{\circ}(\mathrm{NW})$ and $22.5^{\circ}$ (NNE) showed a reasonable amount of observations.

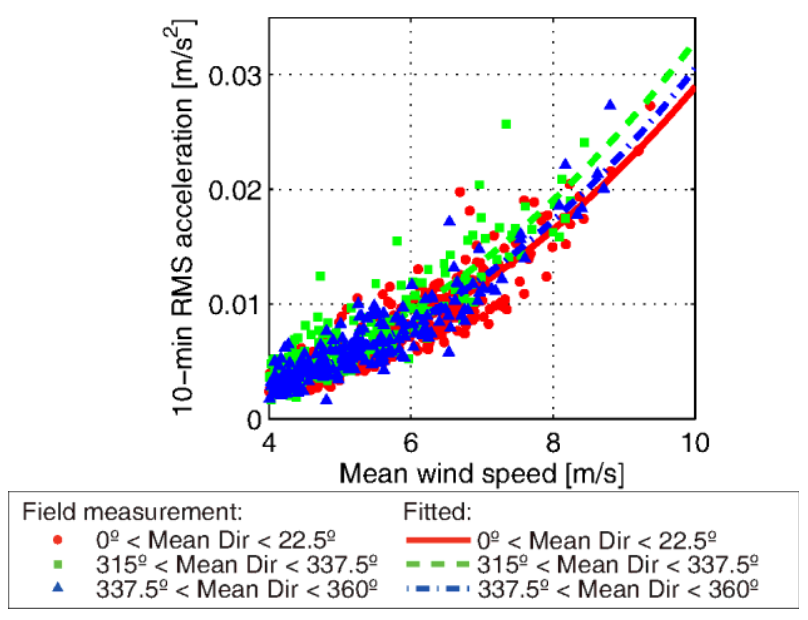

Figure 33. Relationship between mean wind speed from 3 dominant wind directions and 10-min RMS acceleration 
The acceleration level observed is nearly $0.03 \mathrm{~m} / \mathrm{s}^{2}$ RMS and $0.13 \mathrm{~m} / \mathrm{s}^{2}$ maximum for the higher wind speeds. The general trend of increase of the vertical RMS acceleration response with the mean wind speed is characteristic of a turbulence buffeting model, where the vibration mechanism is controlled by turbulent random pressure fluctuations [26].

\section{Conclusions}

The paper reviewed the author's experience in the dynamic testing of cable structures, discussing different purposes and approaches to identify cable force, assess damping and vibrations, and to monitor cable structures. The huge power of presently available instrumentation systems, identification algorithms, and the increased storage and data transmission capacities have enabled researchers and practitioners to develop tools to explore the complex dynamic behaviour of cable structures. The automatic identification of modal parameters, the assessment of response and the different correlations with wind and temperature provide an extremely powerful means to support the field validation of consecrated design tools entirely developed on the basis of wind tunnel tests.

\section{Acknowledgements}

The research work described in the paper has been developed in the context of the activities of the Laboratory of Vibrations and Monitoring and used funds from the National Science Foundation FCT through the projects PTDC/ECM/102087/2008 and PTDC/ECM/109862/2009. The authors acknowledge also the collaboration of Prof. Carmelo Gentile in the tests conducted at the Muge antenna.

\section{References}

1. Mars Ph. and Hardy D. Mesure des Efforts dans les Structures a Cables. Annales TP Belgique 6, 515-531 (1985)

2. Caetano E. Cable Vibrations in Cable-stayed Bridges. SED 9, IABSE (2007)

3. Robert J-L., Bruhat D, and Gervais J-P. Mesure de la Tension des Câbles par Méthode Vibratoire. Bulletin des L.P.C., LCPC, 173, 1991, pp. 109-114 (1991)

4. Casas J. . A Method for Measuring Cable Forces: the Cable-Stayed Alamillo Bridge. Structural Engineering International, 4, No. 4, pp. 235-240 (1994)

5. Cunha, A. And Caetano, E. Dynamic Measurements on Stay Cables of Cable-Stayed Bridges using an Interferometry Laser System. Experimental Techniques, American Society for Experimental Mechanics (SEM), 23, No. 3, pp.38-43 (1999)

6. Adão da Fonseca A., Bastos R., Cunha A. and Caetano E. Monitoring of temporary cables in Infante D. Henrique Bridge. Int. Conf. Structural Health Monitoring, Paris (2002)
7. Caetano, E., Bartek, R. Magalhães, F., Keenan, C., Tryppick, G. Assessment of Cable Forces at the London 2012 Olympic Stadium Roof, Structural Engineering International, SEI / IABSE, 4, pp. 489500 (2013)

8. Zui H., Shinke T. And Namita Y. Practical Formulas for Estimation of Cable Tension by Vibration Method. J. Structural Engineering, ASCE, 122, No. 6, pp. 651-656 (1996)

9. Gautier Y. Moretti C. And Cremona C. Universal Curves for a Practical Estimation of Cable Tension by Frequency Measurements. Experimental Vibration Analysis for Civil Engineering Structures, EVACES'05, Bordeaux, pp. 261-268 (2005)

10. Mehrabi A. And Tabatabai A. A Unified Finite Difference Formulation for Free Vibration of Cables. J. Structural Engineering, 124, No. 11, pp. 13131322 (1998)

11. Cremona C. Tension Determination in Cables: A Practical Tool with Endless Discussions. 8th International Symposium on Cable Dynamics, Paris (2009)

12. Geier R., De Roeck G. And Petz J. Cable Force Determination for the Danube Channel Bridge in Vienna. Structural Engineering International, 3, pp. 181-185 (2005)

13. Kim B, H, Park T. Estimation of Cable Tension Force using the Frequency-based System Identification Method. J. Sound and Vibration, 304, pp. 660-676 (2007)

14. Ni Y. Q., Ko J. M. And Zheng G. Dynamic Analysis of Large-diameter Sagged Cables Taking Into Account Flexural Rigidity. J Sound and Vibration, 257 (2), pp. 301-319 (2002)

15. Irvine, H. M. Cable Structures. The MIT Press (1981)

16. Ceballos M. A., And Prato C. A. Determination of the Axial Force on Stay Cables Accounting for their Bending Stiffness and Rotational End Restraints by Free Vibration Tests. J. Sound and Vibration, 317, pp. 127-141 (2008)

17. Magalhães, F., Caetano, E. \& Cunha, A. Challenges in the application of Stochastic Modal Identification methods to a cable-stayed bridge. $J$ Bridge Engineering, ASCE, 12, No.6, pp.746-754 (2007)

18. Caetano, E., Magalhães, F., Cunha, A. Ponte sobre o rio Arade- Variante à E.N. 125 em Portimão: Estudos para avaliação das características dinâmicas. Consultancy report for A. Rito (2007) (in Portuguese).

19. Caetano, E. and Cunha, A. Identification of Parametric Excitation at the International Guadiana Bridge. Int. Conf. Cable Dynamics. Santa Margherita, Italy ( 2003)

20. Caetano, E., Silva, S., Bateira, J. A vision system for vibration monitoring of civil engineering structures. Exp. Techniques, SEM, 35, No. 4, pp. 74 - 82 (2011)

21. Furtado, R., Quinaz, C. Bastos, R. New Braga Municipal Stadium, Braga. Structural Engineering International, SEI, 15, No. 2, pp. 72-76, IABSE (2005)

22. Martins, N., Caetano, E., Amador, S., Magalhães, F., Cunha, A. Dynamic monitoring of a stadium 
suspension roof: wind and temperature influence on modal parameters and structural response", Engineering Structures, 59, pp. 80-94 (2014)

23. Magalhães, F., Cunha, A., Caetano, E. Online automatic identification of the modal parameters of a long span arch bridge. Mechanical Systems and Signal Processing, 23, no. 2, pp. 316-329 (2009)

24. Caetano, E., Cunha, A., Magalhães, F. Numerical and experimental studies of Braga sports stadium suspended roof. J Structure Infrastructure Eng., 6, No. 6, pp. 715-724 (2010)

25. Macdonald, J. Separation of the contributions of aerodynamic and structural damping in vibrations of inclined cables. $J$ Wind Engineering Ind Aerodynamics, 90, no. 1, pp. 19-39 (2002)

26. Shigehiko, S., Nakamura, T., Inada, F., Kato, M. Flow-induced vibrations: classifications and lessons from practical experiences. Elsevier Science (2008) 